\title{
Papel Humanitário da Enfermagem Frente aos Cuidados Direcionados aos Portadores da Doença de Alzheimer e Seus Familiares
}

\author{
Silva, Raymara Alves da; Silva, Liniker Scolfild R. da; Fonsêca, Jéssica Ramalho da; \\ Ramos, Ana Raquel Xavier; Correia, Nathália da Silva; Cordeiro, Eliana Lessa
}

Agência de Cursos — raymaraalves@yahoo.com.br

Introdução: com o aumento no processo de envelhecimento populacional brasileiro, e consequentemente no número de idosos, observou-se um crescimento acentuado das doenças crônico - degenerativas, como a doença de Alzheimer. Este agravo vem sendo responsável por danos às habilidades físicas e mentais no idoso acarretando assim um déficit na qualidade de vida desta população e na maioria das vezes dos seus cuidadores. o enfermeiro e sua equipe podem ser personagens decisivos sobre a avaliação da capacidade funcional deste idoso, ajudando não só o portador da doença, mas também a família que estará presente. Este processo muitas vezes torna-se árduo pois ainda existe o desconhecimento dessa patologia e os estágios que o idoso irá vivenciar. Diante desta temática, o cuidado humanizado da enfermagem direcionado ao portador de Alzeheimer e seu familiares, vem possibilitando uma melhoria na inter-relação paciente-família de forma menos desgastante possível. Objetivo: Descrever a atuação do enfermeiro frente aos cuidados humanizados aos portadores doença de Alzheimer e seus familiares. Método: Trata-se de um estudo do tipo revisão integrativa da literatura científica brasileira, no qual partiu-se da leitura e reflexão das publicações nacionais dos últimos 03 (três) anos, utilizando os descritores "enfermagem"; "cuidados"; "humanitários" e "doença senil", sendo selecionado um total de 06 (seis) artigos, dos últimos 05 (cinco) anos, disponíveis na íntegra e na língua portuguesa, indexadas na Biblioteca Virtual de Saúde - BVS: SCIELO e LILACS. Resultados: Os resultados apontaram que o gênero, a idade, a escolaridade, e o estágio de demência são fatores considerados importantes para avaliação da regressão múltipla dos idosos em questão. Outro ponto importante é que os idosos em estágios mais avançados de demência demonstram piores escores de desenvolvimento na sua rotina de atividades diárias e essenciais, demonstrando claramente a necessidade e compreensão de quem os assiste. Conclusão: a sistematização da assistência de enfermagem pode identificar problemas, auxiliar o desenvolvimento de planejamento, priorizar o apoio da família, executar o plano assistencial. Este estudo fez refletir a prática humanitária da enfermagem, suas contribuições no restabelecimento e organização de uma nova rotina adaptada ao saber fazer novo que se apresenta como desafio a cada dia ao portador de Alzheimer e sua família.

Silva, Raymara Alves da; Silva, Liniker Scolfild R. da; Fonsêca, Jéssica Ramalho da; Ramos, Ana Raquel Xavier; Correia, Nathália da Silva; Cordeiro, Eliana Lessa. Papel Humanitário da Enfermagem Frente aos Cuidados Direcionados aos Portadores da Doença de Alzheimer e Seus Familiares. In: Anais do Congresso Internacional de Humanidades \& Humanização em Saúde [= Blucher Medical Proceedings, num.2, vol.1]. São Paulo: Editora Blucher, 2014. ISSN 2357-7282

DOI $10.5151 /$ medpro-cihhs-10714 